\title{
Bacterial community of biofilms developed under different water supply conditions in a distribution system
}

\author{
Huifang Sun ${ }^{\mathrm{a}, \mathrm{b}}$, Baoyou Shi ${ }^{\mathrm{a}, *}$, Yaohui Bai ${ }^{\mathrm{a}}$, Dongsheng Wang ${ }^{\mathrm{a}}$ \\ a State Key Laboratory of Environmental Aquatic Chemistry, Research Center for Eco-Environmental Sciences, Chinese Academy of Sciences, 18 Shuangqing Road, P.O. Box 2871, \\ Beijing 100085, China \\ ${ }^{\mathrm{b}}$ University of Chinese Academy of Sciences, Beijing 100039, China
}

\section{H I G H L I G H T S}

- Bacterial community in biofilms with different water sources was investigated.

- Biofilm with surface water had higher Firmicutes than that with groundwater.

- Higher iron corrosion bacteria were presented in biofilms with surface water.

- Alkalinity and COD correlated with Proteobacteria and Firmicutes, respectively.

- Corrosive bacteria could affect the thick or tubercle corrosion scale formation.

\section{A R T I C L E I N F O}

\section{Article history:}

Received 15 July 2013

Received in revised form 25 September 2013

Accepted 3 November 2013

Available online 26 November 2013

\section{Keywords:}

Drinking water distribution systems (DWDS)

Biofilm

Bacterial community

Corrosion scale

454 pyrosequencing

Water source

\begin{abstract}
A B S T R A C T
In order to understand the bacterial community characteristics of biofilms developed under different finished water supply histories in drinking water distribution systems (DWDS), biofilm samples on different type of iron corrosion scales in a real DWDS were collected and systematically investigated using 454 pyrosequencing of $16 \mathrm{~S}$ rRNA gene. The richness and diversity estimators showed that biofilms formed in DWDS transporting finished groundwater $(\mathrm{GW})$ had the lowest level of bacterial diversity. From phylum to genus level, the dominant bacterial groups found in the biofilms under finished surface water (SW) and GW conditions were distinct. Proteobacteria was the dominant group in all biofilm samples (in the range of 40\%-97\%), but was relatively higher in biofilms with GW. The relative abundance of Firmicutes in biofilms with SW (28\%-35\%) was significantly higher $(\mathrm{p}<0.01)$ than that in biofilms with GW $(0.5 \%-2.88 \%)$. Statistical analysis (Spearman's rank) revealed that alkalinity and chemical oxygen demand $\left(\mathrm{COD}_{\mathrm{Mn}}\right)$ positively correlated with the relative abundance of Proteobacteria and Firmicutes, respectively. The abundance of sequences affiliated to iron-reducing bacteria (mainly Bacillus) and iron-oxidizing bacteria (mainly Acidovorax) were relatively higher in biofilms with SW, which might contribute to the formation of much thicker or tubercle-formed corrosion scales under SW supply condition. Several potential opportunistic pathogens, such as Burkholderia fungorum, Mycobacterium neoaurum, Mycobacterium frederiksbergense were detected in the biofilms.
\end{abstract}

(c) 2013 Elsevier B.V. All rights reserved.

\section{Introduction}

Finished water conforming to high water quality standards does not necessarily ensure its safety at the consumers' tap after long-distance pipe transportation (Eichler et al., 2006). Microorganisms cannot be removed completely even passing through multibarrier treatment processes, and the re-growth of microorganisms could be sustained during distribution; in addition, treatment failure and pipe contamination may also lead to severe microbial proliferation in drinking water distribution systems (DWDS) (Reynolds et al., 2008). Biofilm developed on the internal surface of distribution pipes could shelter opportunistic

\footnotetext{
* Corresponding author. Tel./fax: + 861062849138 .

E-mail address: byshi@rcees.ac.cn (B. Shi).
}

pathogens and act as reservoir of microorganisms in DWDS (Berry et al., 2006). The existence of biofilm in DWDS may have multiple adverse effects on the water quality by supporting nitrification when chloramination applied (Hong et al., 2010), speeding depletion of disinfection agents (Simoes et al., 2010), protecting and supporting opportunistic pathogens (Martiny et al., 2003; Eichler et al., 2006).

In addition, some microorganisms on metal surfaces can affect the kinetics of cathodic and/or anodic corrosion reactions, and can also modify the corrosion products considerably, thus lead to acceleration or inhibition of corrosion processes (Beech and Sunner, 2004). Known types of bacteria associated with iron corrosion are sulfate-reducing bacteria (SRB), sulfur-oxidizing bacteria (SOB), iron-reducing bacteria (IRB), iron-oxidizing bacteria (IOB) and bacteria secreting organic acids and slime (Wang et al., 2012; Emde et al., 1992). SRB is usually 
associated with anaerobic iron corrosion by producing hydrogen sulfide $\left(\mathrm{H}_{2} \mathrm{~S}\right)$ as a corrosive agent. Under certain condition, $\mathrm{H}_{2} \mathrm{~S}$ may increase rapidly at a local anaerobic area beneath iron-rich tubercles, and the interaction between SRB and IOB could accelerate the iron corrosion process (Xu et al., 2007). SOB is responsible for the release of sulfuric acid and dissolved metals (Korehi et al., 2013). Furthermore, the enzymatic activity within biofilm was demonstrated to play an important role in the ennoblement of metals (Liao et al., 2010), and $\mathrm{H}_{2} \mathrm{O}_{2}$ produced by the microorganism was proved to increase the open circuit potential (Washizu et al., 2004). Whereas, other researchers found that IRB might have the capacity of inhibiting corrosion (Wang et al., 2012; Zuo et al., 2005), and the inhibition was considered mainly due to the extracellular polymeric substances (EPS) of the biofilm, which could impede the dissolution of ferrous corrosion products (Videla and Herrera, 2009).

Numerous studies have been dedicated to reveal bacterial communities in DWDS, and the effects of sampling location and pipe material have been reported (Martiny et al., 2003; Liu et al., 2012a). Existing investigation on bacterial communities in DWDS indicated that populations are quite different from source water to tap water (Eichler et al., 2006). Concentration of organic compounds, chlorine levels, water temperature, physicochemical characteristics of pipe materials and the age of biofilm can influence bacterial community in DWDS (Martiny et al., 2003). Moreover, the presence of potential opportunistic pathogens had been detected at some endpoints of DWDS, such as tap water (Kormas et al., 2010), faucets (Liu et al., 2012b), meters (Hong et al., 2010) and showerheads (Feazel et al., 2009).

Due to limited access and high cost involved in sampling biofilm within DWDS, simulated DWDS or the end-points are often used in the previous researches to study the microbial communities. However, the formation of biofilm requires several years before steady state is achieved, which limits the relevance of short-term model studies (Martiny et al., 2003). In addition, Bachmann and Edyvean (2005) reported that the origin of raw water played certain roles in determining the bacterial community of biofilms in DWDS, but the current information on the differences of biofilm community with different water sources, such as surface water (SW) and groundwater (GW) sources is still scant. Furthermore, many studies based on molecular methods such as $16 \mathrm{~S}$ rRNA gene clone libraries (Liu et al., 2012a) and gene fingerprinting arrays (Eichler et al., 2006) could not represent the complete picture of the diversity and bacterial community in DWDS due to the limited throughput. Thus, the real bacterial diversity and community need to be explored in more detail. With the development of highthroughput sequencing technology, such as the 454 pyrosequencing, as well as the application of multivariate statistical tools, it is possible to obtain better taxonomic identification of the bacterial populations of biofilms in DWDS.

In the present study, the microbiological composition of biofilms under different finished water supply histories in a real large-scale DWDS was determined using 454 pyrosequencing. Biofilm samples on different types of iron corrosion scales were collected from seven different sites. The main objective of this work was to provide an in-depth investigation of the microbial community of biofilms with different type of water sources in DWDS; the interrelationships among water quality, bacterial community and corrosion scale characteristics were also discussed.

\section{Materials and methods}

\subsection{Sample collection}

Seven old unlined cast iron pipe sections (approximately 20 years old) were excavated from seven different DWDS sites in a northern city of China. Detailed procedures of pipe section collection are provided in Appendices (A.1). Of the seven pipes, four pipes (Pipe-A, B, C, D) were excavated on May 2011, and the other three (Pipes-E, F, and G) were excavated on March 2013.

These pipes were supplied with finished waters from different water sources, except Pipes-B and C. Pipes-A, B, and C were transporting SW (Pipe-A: SW-1; Pipe-B, C: SW-4); Pipes-D and E were transporting blended surface and ground waters, since they were excavated from the boundary of surface and ground water service areas (Pipe-D: SW2/GW-2; Pipe-E: SW-3/GW-2); Pipes-F and G were transporting GW (Pipe-F: GW-1; Pipe-G: GW-3). Pipes-B and C were supplied with the same water source but excavated at two different sites. Water sources, main finished water quality parameters and treatment processes of corresponding water treatment plants are summarized in Table 1 . The analysis methods for water quality were provided in Appendices (A.2). Immediately after collection, pipe sections were rapidly transported to laboratory and biofilm samples were taken within $24 \mathrm{~h}$.

\subsection{DNA extraction}

Approximately $20.0 \mathrm{~cm}^{2}$ of biofilm samples was scraped using sterile spatulas from the top, middle and bottom of each pipe section. To better represent the biofilm community characteristics of each pipe, three parts of biofilm samples from one pipe section were combined for DNA extraction. Before DNA extraction, the biofilm samples were washed three times using sterile phosphate-buffered saline $(\mathrm{pH} 7.0)$ and centrifugated at $10,000 \mathrm{r} \cdot \mathrm{min}^{-1}(10,400 \mathrm{~g})$ at $4{ }^{\circ} \mathrm{C}$ for $15 \mathrm{~min}$. After centrifugation, DNA was extracted using a FastDNA spin kit for soil (Obiogene, USA) facilitated with the FastPrep-24 bead beater system following the manufacturer's instructions, and then quantified with a Nanodrop-1000 spectrophotometer (Thermo Scientific, USA). The obtained DNA concentrations were in the range of 36-160 ng/ $\mathrm{LL}$. All DNA samples were stored at $-80{ }^{\circ} \mathrm{C}$ until further processing.

\subsection{Pyrosequencing}

The V1-V3 region within the 16S rRNA gene fragment was amplified from biofilm DNA by PCR using barcoded universal primers $8 \mathrm{~F}\left(5^{\prime}\right.$ AGAGTTTGATCCTGGCTCAG-3') and 533R (5'-TTACCGCGGCTGCTGG (AC- $\left.3^{\prime}\right)$ containing the $\mathrm{A}$ and $\mathrm{B}$ sequencing adaptors, respectively (454 Life Science) (Bai et al., 2012). PCR amplification was performed as described previously (Wu et al., 2012). Positive PCR products were purified with AxyPrep DNA Gel Extraction Kit (Axygen, USA). The DNA concentration of purified amplicons was measured by TBS-380 Fluorometer (Turner Biosystems, USA). Prior to sequencing, the amplifications from each reaction mixture were mixed in equal amounts based on concentration and subjected to emulsion PCR, and amplicon libraries were generated as recommended by 454 Life Sciences. Sequencing was performed for the primer B end using the 454/Roche B (Roche Diagnostics, USA) sequencing primer kit using Genome Sequencer GS-FLX according to protocols described by Margulies et al. (2005).

Pyrosequencing flowgrams were converted to sequence reads using MOTHUR software (http://www.mothur.org/) and then analyzed using UCHIME (http://drive5.com/uchime) standard pipeline. Sequence reads were initially filtered and denoised for removing low quality or ambiguous reads (Bai et al., 2012). Then the treated sequences were subjected to systematic checks to remove replicates, duplicates, barcodes, primer sequences and low-quality reads. Briefly, high quality sequences (>200 bp in length, quality score $>25$, exact match to barcode and primer, and containing no ambiguous characters) were remained with an average length of $469 \mathrm{bp}$.

\subsection{Statistical analysis}

Sequences were clustered into the operational taxonomic units (OTUs) by setting a 0.03 distance limit (equivalent to $97 \%$ similarity) using the MOTHUR program. The species richness estimators 
Table 1

Water sources, finished water quality, and main treatment processes. ${ }^{\mathrm{a}}$

\begin{tabular}{|c|c|c|c|c|c|c|c|}
\hline Water source & $\mathrm{SW}^{\mathrm{b}}-1$ & SW-2 & SW-3 & SW-4 & $G W^{\mathrm{c}}-1$ & GW-2 & GW-3 \\
\hline $\mathrm{pH}$ & 7.85 & 7.49 & 7.80 & 8.04 & 7.71 & 7.40 & 7.80 \\
\hline Temperature $\left({ }^{\circ} \mathrm{C}\right)$ & 20 & 15 & 16 & 9 & 14 & 17 & 7 \\
\hline Turbidity (NTU) & 0.15 & 0.24 & 0.13 & 0.19 & 0.15 & 0.29 & 0.24 \\
\hline Alkalinity $(\mathrm{mg} / \mathrm{L} \mathrm{CaCO} 3)$ & 140 & 150 & 140 & 165 & 200 & 225 & 205 \\
\hline Sulfate $(\mathrm{mg} / \mathrm{L})$ & 39.8 & 33.9 & 41.6 & 80.7 & 22.0 & 38.1 & 19.1 \\
\hline Chloride (mg/L) & 17.7 & 17.3 & 21.1 & 23.7 & 16.4 & 15.0 & 13.7 \\
\hline Nitrate (mg/L N) & 1.2 & 3.4 & 1.2 & 1.6 & 1.2 & 4.8 & 5.2 \\
\hline Nitrite (mg/L N) & $<0.001$ & $<0.001$ & $<0.001$ & 0.001 & $<0.001$ & $<0.001$ & 0.001 \\
\hline Ammonium (mg/L N) & $<0.02$ & $<0.02$ & $<0.02$ & 0.06 & 0.08 & $<0.02$ & $<0.02$ \\
\hline $\mathrm{COD}_{\mathrm{Mn}}\left(\mathrm{mg} / \mathrm{L} \mathrm{O}_{2}\right)$ & 1.4 & 0.95 & 0.87 & 1.1 & 0.55 & 0.55 & 0.32 \\
\hline Residual chlorine $\left(\mathrm{mg} / \mathrm{L} \mathrm{Cl}_{2}\right)$ & 0.70 & 0.70 & 0.65 & 0.80 & 0.65 & 0.70 & 0.55 \\
\hline $\mathrm{Fe}(\mathrm{mg} / \mathrm{L})$ & $<0.05$ & 0.11 & $<0.05$ & $<0.05$ & $<0.05$ & $<0.05$ & $<0.05$ \\
\hline $\operatorname{Mn}(\mathrm{mg} / \mathrm{L})$ & $<0.001$ & $<0.001$ & $<0.001$ & $<0.001$ & $<0.001$ & $<0.001$ & $<0.001$ \\
\hline $\mathrm{Ca}\left(\mathrm{mg} / \mathrm{L} \mathrm{CaCO}{ }_{3}\right)$ & 104 & 110 & 113 & 150 & 125 & 213 & 147 \\
\hline $\mathrm{Mg}\left(\mathrm{mg} / \mathrm{L} \mathrm{CaCO}_{3}\right)$ & 78 & 83 & 66 & 93 & 89 & 133 & 92 \\
\hline Main treatment process & $\begin{array}{l}\mathrm{C}-\mathrm{S}-\mathrm{F}^{\mathrm{d}}, \mathrm{GAC}^{\mathrm{e}} \text {, } \\
\text { disinfection }\end{array}$ & $\begin{array}{l}\text { C-S-F BAC, } \\
\text { disinfection }\end{array}$ & $\begin{array}{l}\text { C-S-F, GAC, } \\
\text { disinfection }\end{array}$ & $\begin{array}{l}\text { C-S-F, GAC, } \\
\text { disinfection }\end{array}$ & Disinfection & Disinfection & Disinfection \\
\hline
\end{tabular}

a Water quality parameters were average value of a monthly monitoring data of finished waters at treatment plant.

b SW: surface water.

c GW: groundwater.

d C-S-F: Coagulation-sedimentation-filtration.

e GAC: granular activated carbon adsorption.

f BAC: ozonation-biologically activated carbon adsorption.

(abundance-based coverage estimator [ACE] and Chao1) (Chao and Lee, 1992), Shannon diversity index and Simpson's diversity index were generated in MOTHUR for each sample. Rarefaction and ShannonWiener curves were performed on R (http://www.r-project.org/). Sequences were phylogenetically assigned to taxonomic classifications using MOTHUR via SILVA database (SILVA SSU111, http://www. arb-silva.de) with a confidence threshold of $80 \%$. After phylogenetic allocation of the sequences down to the phylum, class and genus level, relative abundance of a given phylogenetic group was calculated (Lu et al., 2012). To correlate bacterial community with water properties, Spearman's rank was performed by using the SPSS 18.0 (SPSS Inc., USA). Redundancy analysis (RDA) was performed using the vegan package of R. Distribution heatmap of genus-level bacterial communities was implemented by vegan package of $\mathrm{R}$ in Linux. The bacterial phylogenetic tree on the left was created by approximatelymaximum-likelihood method using FastTree (Price et al., 2010), and the relationship among samples was determined by Bray-Curtis and complete clustering method.

\section{Results and discussion}

\subsection{Morphology of corrosion scales and properties of finished water quality}

The appearances of corrosion scales on iron pipe surfaces with different water supply conditions are shown in Appendices (Fig. A.1). Corrosion scales of Pipes-A, B, C, D and E are the typical four-layered thick corrosion scales or tubercles. The micro-structural features of such kind of tubercle-formed and thick corrosion scales had been described in detail (Sarin et al., 2004; Yang et al., 2012), which included a loosely attached top surface layer, a hard shell-like layer, a porous core and corroded floor (Fig. A.1 h). Compared with these five pipes, corrosion scales on Pipes-F and $G$ were much thinner and relatively smooth (nearly no corrosion tubercles on the inner pipe surfaces). Sarin et al. (2004) and Yang et al. (2012) found that magnetite $\left(\mathrm{Fe}_{3} \mathrm{O}_{4}\right)$ and goethite $(\alpha-$ $\mathrm{FeOOH}$ ) were the main constitutes of the hard shell-like layers. Yang et al. (2012) further observed that the mass ratio of magnetite/goethite of corrosion scales from SW service areas was much greater than that of corrosion scales from GW service areas, moreover, the relatively thin and smooth scales were mostly found in GW service areas (thin scales had no $\mathrm{Fe}_{3} \mathrm{O}_{4}$ detected or with much lower $\mathrm{Fe}_{3} \mathrm{O}_{4}$ content).

As shown in Table 1, the finished SW (SW 1-4) were roughly similar, except the temperature of SW-4 was lower than that of the other three. Pipes supplied SW-1, SW-2 and SW-3 were excavated in May 2011, while pipes supplied SW-4 were excavated in March 2013. The sampling time might be the factor causing the temperature difference. Compared with finished SW, the finished GW (GW 1-3) had higher alkalinity, and relatively lower concentration of $\mathrm{COD}_{\mathrm{Mn}}$ and chloride. The sulfate concentrations of SW were higher than those of GW- 1 and GW-3. In addition, the dissolved oxygen (DO) of finished GW (less than $7.0 \mathrm{mg} / \mathrm{L}$ ) was generally lower than those of finished SW (in the range of $8.0-11.0 \mathrm{mg} / \mathrm{L}$ ). The water treatment processes of the SW mainly included coagulation, sedimentation, filtration, granular activated carbon adsorption and chlorine disinfection, while the treatment process of the GW was only chlorine disinfection.

Previous research reported that the origin of raw water had great impact on the bacterial communities in DWDS, and the biostability of GW was greater than that of SW (Bachmann and Edyvean, 2005). Temperature, $\mathrm{pH}$ and organic carbon were considered to be the most important factors affecting bacterial communities (Ndiongue et al., 2005; Bachmann and Edyvean, 2005). Nitrate was also found to induce structural and functional changes in the marine biofilms (Schwermer et al., 2008). In addition, higher DO, chloride and sulfate had been shown to increase water corrosivity, while higher alkalinity had been demonstrated to reduce the corrosion rate (Li et al., 2010). Jang et al. (2010) reported that the bacterial concentration and species diversity in the biofilms were increased with corrosion of the pipe, and adsorption of organic carbon by iron oxide containing corrosion product could promote biofilm growth.

The different treatment processes and treatment efficiency could influence the finished water quality. Optimized (or enhanced) coagulation combined with activated carbon adsorption could effectively remove organic matters, which is the main nutrient of microorganisms. The efficiency of disinfection could be greatly dependent on the disinfectant type, dosage and the contact time.

Therefore, both the water sources and the treatment processes could affect the finished water quality, the bacterial communities and consequently could contribute to the different corrosion scales in DWDS. 


\subsection{Richness and diversity analysis of biofilm samples}

From all seven samples, 84,278 valid sequences and 7508 OTUs at $97 \%$ similarity level were obtained through 454 pyrosequencing analysis. Each of the seven samples contained valid sequences between 10,369 and 13,250 , with the number of OTUs ranging from 642 to 1532 (Table 2). The rarefaction curves indicated that new bacterial phylotypes continued to emerge even after 10,000 reads sampling with pyrosequencing (Fig. A.2). However, the Shannon diversity indices of all samples already reached stable values at the sequencing depth used in this study, which means that most diversity had already been captured although new phylotypes might be expected with additional sequencing (Fig. A. 3). Moreover, Good's coverage revealed that these libraries represented the majority of bacterial 165 rRNA sequences presented in each biofilm sample, with values ranging from 0.92 to 0.98 (Table 2).

The richness and diversity indices were calculated at a $3 \%$ width, as shown in Table 2. The values of ACE and Chao 1 in the samples with SW were significantly higher than those in the samples with GW (Student's $t$-test, $\mathrm{p}<0.01)$. The Shannon $(\mathrm{p}<0.05)$ and Simpson $(\mathrm{p}<0.01)$ diversity indices revealed a comparatively higher level of bacterial diversity in the samples with SW. These results indicated that samples with GW had the relatively lower level of bacterial richness and diversity, compared with other samples. The biofilm communities in DWDS showed a large bacterial diversity, with Shannon diversity indices (3.36-5.29) comparable to those derived from river water or even soil (Cottrell et al., 2005). A total of 346 genera were identified from the seven biofilm samples. In comparison to other investigations for water supply systems using molecular method, e.g. 16S rRNA gene clone libraries (Liu et al., 2012a), gene fingerprinting arrays (Eichler et al., 2006), in situ hybridization (Williams et al., 2004), the present analysis of 16 S rRNA gene sequencing demonstrated a more diverse bacterial genus in DWDS biofilms.

\subsection{Taxonomic composition of biofilm samples}

Of all filtered sequences, 22 different bacterial phyla were identified across the seven biofilm samples with MOTHUR via SILVA database. Proteobacteria (accounting for 40\%-97\%) was the dominant phylum in all samples, and mainly consisted of four classes (Alphaproteobacteria, Betaproteobacteria, Gammaproteobacteria and Deltaproteobacteria). In addition to Proteobacteria, Firmicutes, Actinobacteria, Bacteroidetes and Cyanobacteria were also identified in all biofilm samples.

The bacterial community of seven biofilm samples in both phylum and class levels is presented in Fig. 1. In the samples (F and G) with GW, the relatively abundance of Proteobacteria (91\%-97\%) was higher than that in the samples with SW and blends (40\%-67\%). Previous research reported that Betaproteobacteria occur almost exclusively in freshwater environment, while Alphaproteobacteria are more abundant in marine than in freshwater (Glockner et al., 1999). Interestingly, this

Table 2

Coverage and diversity indices of bacterial 16S rRNA gene libraries of the seven biofilm samples $(\alpha=0.03)$.

\begin{tabular}{llllllll}
\hline Sample & Reads & OTU & Ace & Chao 1 & Coverage & Shannon & Simpson \\
\hline A & 11,601 & 1175 & 2091 & 1849 & 0.958452 & 5.29 & 0.0184 \\
B & 13,102 & 1532 & 2496 & 1804 & 0.926881 & 4.75 & 0.0341 \\
C & 12,540 & 1278 & 2146 & 1474 & 0.937480 & 4.55 & 0.037 \\
D & 11,834 & 1001 & 1879 & 1607 & 0.963580 & 4.93 & 0.0234 \\
E & 10,369 & 1004 & 2532 & 1828 & 0.951201 & 4.72 & 0.0333 \\
F & 11,582 & 642 & 1636 & 1166 & 0.972285 & 3.36 & 0.0975 \\
G & 13,250 & 876 & 1480 & 1079 & 0.964679 & 3.84 & 0.0934 \\
\hline
\end{tabular}
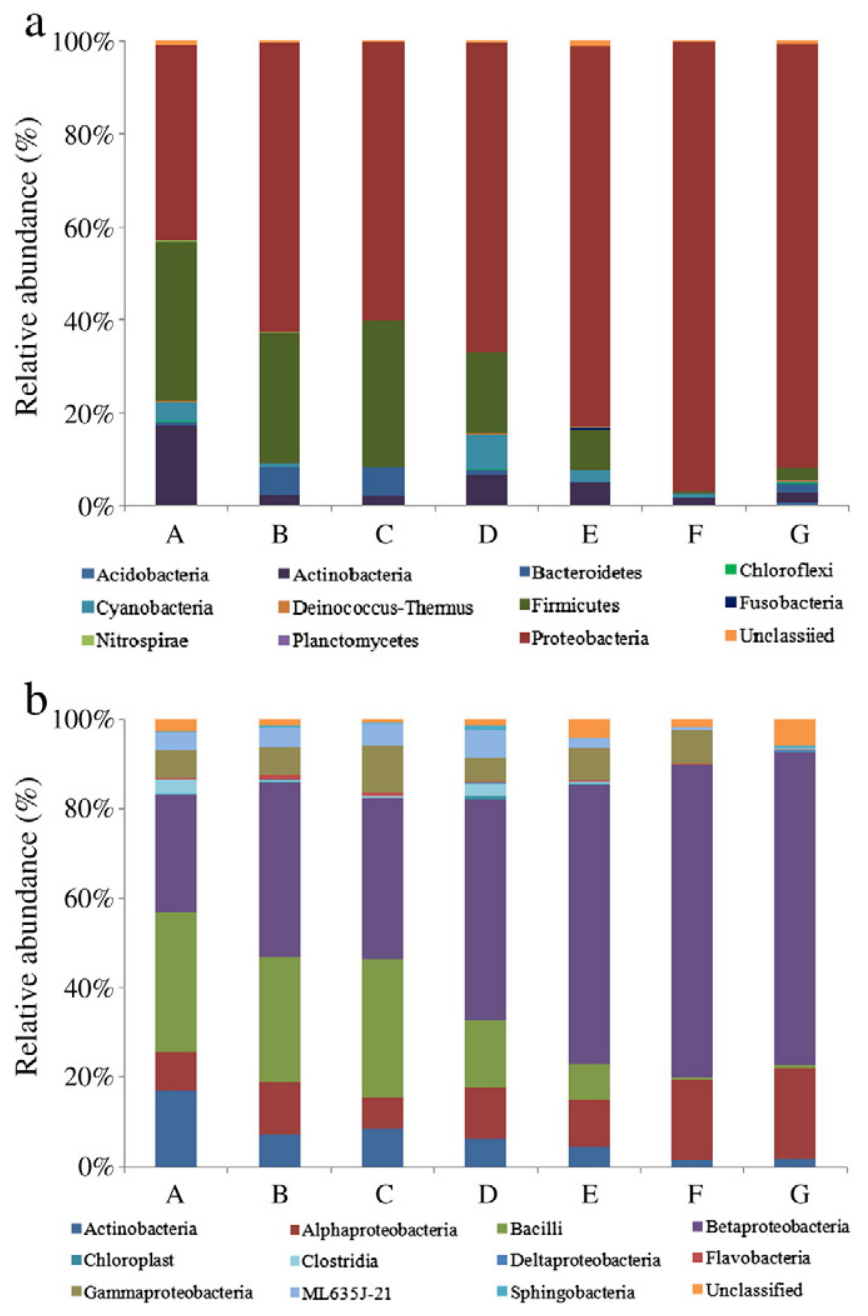

Fig. 1. Bacterial community of seven biofilm samples. Relative abundances of the 11 most abundant groups within different communities are shown in (a) phylum level; (b) class level. Sequences that could not be classified into any known group and other smaller phyla (classes) are assigned as "Unclassified". The source of the samples: A: SW-1; B, C: SW-4; D: SW-2/GW-2; E: SW-3/GW-2; F: GW-1; G: GW-3.

pyrosequencing results showed that Betaproteobacteria (26\%-70\%) was dominant in most of the samples, while Alphaproteobacteria $(8 \%-21 \%)$ was another abundant class. The abundances of these two classes were relatively higher in the samples with GW, compared with other samples (Fig. 1b). Other investigations for water supply systems also demonstrated that Alphaproteobacteria was one of the main populations in bacterial communities (Liu et al., 2012b; Hong et al., 2010).

Firmicutes was the second largest bacterial group (28\%-35\%) in the samples (A, B and C) with SW, but was present at much lower proportions in the samples (F and G) with GW (0.50\%-2.88\%). Firmicutes was mainly consisted of Bacilli and Clostridia at the class level, and the relative abundances of these two classes in the samples with SW (Bacilli: 27\%-32\%; Clostridia: $0.40 \%-3.22 \%$ ) were much higher than that in the samples with GW (Bacilli: 0.5\%-0.6\%; Clostridia: 0.01\%-0.20\%). Bacilli and Clostridia include numerous members capable of producing endospores, which have high resistance to a variety of environment challenges, such as heat, solvents, oxidizing agents, UV irradiation and desiccation (Abecasis et al., 2013). The resilience of the endospores allows them to remain viable in the harsh environment for long periods (Abecasis et al., 2013), and contribute to their survival and proliferation in chlorinated environments in DWDS (Bachmann and Edyvean, 2005). 
Evaluation at the genus level showed that Betaproteobacteria in the biofilm samples mainly consisted of Acidovorax, Burkholderia, Delftia, Ralstonia, Variovorax and Neisseria (Fig. 2, Table A.1), Bacilli and Clostridia mainly consisted of Bacillus and Clostridium respectively. Of these genera, Burkholderia and Delftia were abundant in all biofilm samples, Acidovorax, Ralstonia, Bacillus and Clostridium were relatively higher in the samples with SW and the blends. Acidovorax comprises metabolically diverse species capable of using a wide range of naturally occurring compounds (Hong et al., 2010). With respect to the DWDS, Acidovorax had been found to play important roles in iron corrosion, such as enhancing biofilm formation in flowing environment (Li et al., 2010). Members within the genera Bacillus and Clostridium are not only known as sporeforming organisms, but also could affect iron corrosion and modify the corrosion products (Kostka et al., 2002; Emde et al., 1992). Besides, it should be noticed that the genus Mycobacterium was present at relatively higher proportions in samples with SW and blends (except B and C). Mycobacteria are generally resistant to disinfectants due to their complex cell wall (Liu et al., 2012b). The Mycobacteria were possibly associated with human health, and the potential pathogenic Mycobacteria in DWDS should arouse more attention.

\subsection{Relationship between bacterial community and water quality}

Correlation analysis (Table A.2) showed that the relative abundance of Proteobacteria was positively correlated with alkalinity $(\mathrm{R}=0.94$, $\mathrm{p}<0.01)$ and negatively correlated with $\operatorname{COD}_{\mathrm{Mn}}(\mathrm{R}=-0.93$, $\mathrm{p}<0.01)$. While Firmicutes was negatively correlated with alkalinity $(\mathrm{R}=-0.93, \mathrm{p}<0.01)$ and positively correlated with $\mathrm{COD}_{\mathrm{Mn}}$ $(\mathrm{R}=0.95, \mathrm{p}<0.05)$. Actinobacteria was positively correlated with temperature $(\mathrm{R}=0.83, \mathrm{p}<0.05)$. At the class level, Alphaproteobacteria and Betaproteobacteria were both significantly correlated with alkalinity $(\mathrm{R}=0.80,0.95)$ and $\mathrm{COD}_{\mathrm{Mn}}(\mathrm{R}=-0.83,-0.96)$. Bacilli had a significant positive correlation with sulfate $(R=0.80)$, chloride $(R=0.76)$ and $\operatorname{COD}_{\mathrm{Mn}}(\mathrm{R}=0.94)$, and negatively correlated with alkalinity

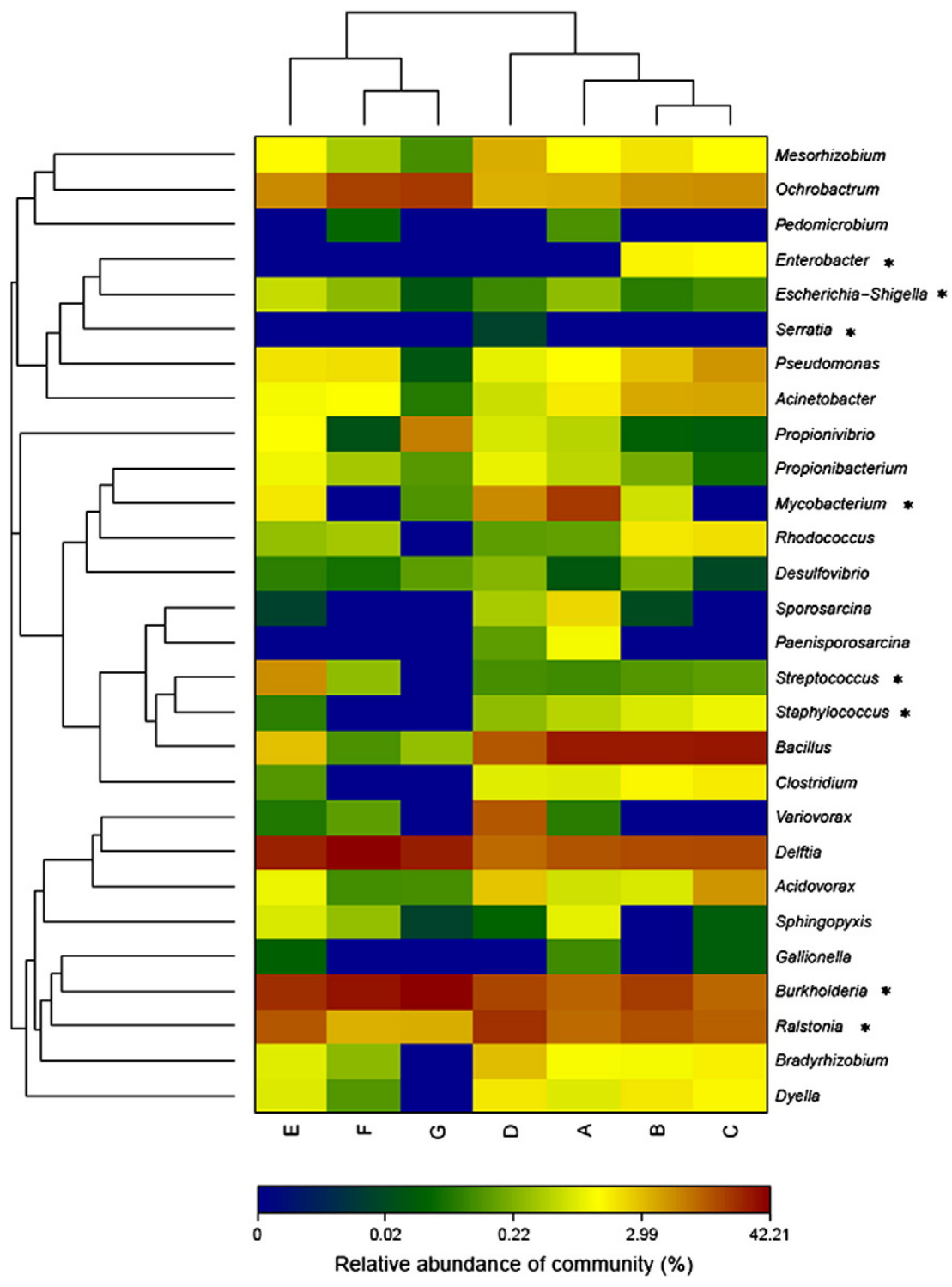

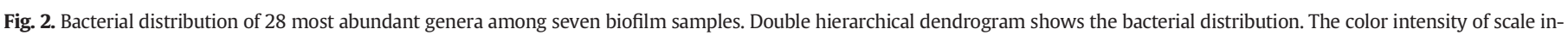
dicates relative abundance of each genus. *Many of sequences related to these genera exhibit high similarity to potential opportunistic pathogens. 
( $\mathrm{R}=-0.92$ ). The value of $\mathrm{p}$ was less than 0.05 for all cases in the class level. The genera Burkholderia was also correlated with alkalinity $(\mathrm{R}=0.86)$ and $\mathrm{COD}_{\mathrm{Mn}}(\mathrm{R}=-0.91)$, but Delftia was not found to be significantly correlated with any factors. In common with Firmicutes, Bacillus was negatively correlated with alkalinity $(R=-0.91$, $\mathrm{p}<0.01)$ and positively correlated with $\mathrm{COD}_{\mathrm{Mn}}(\mathrm{R}=0.94, \mathrm{p}<0.05)$.
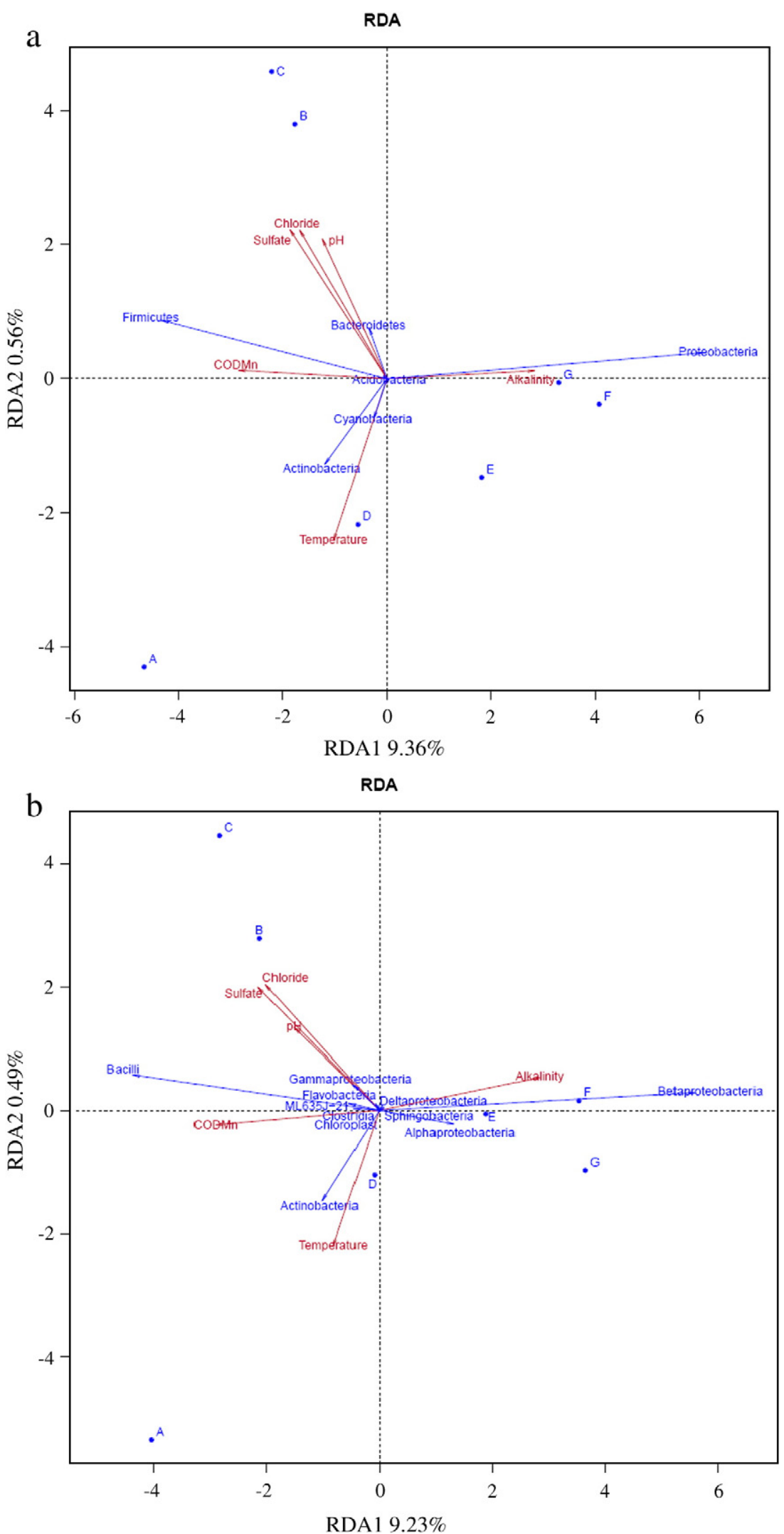

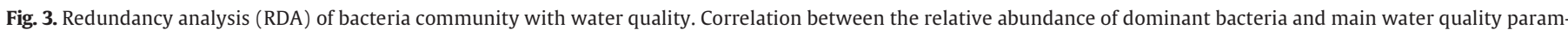
eters (a: in phylum level; b: in class level). 
RDA results indicated that, of the parameters examined, alkalinity and $\operatorname{COD}_{\mathrm{Mn}}$ could explain the greatest amount of variability in the biofilm bacterial community. RDA analysis established a similar correlation between Proteobacteria and alkalinity, Firmicutes and $\operatorname{COD}_{\mathrm{Mn}}$ (Fig. 3).

Although statistical relationships could be established as above, understanding the effect of water quality on bacterial community still need further well designed study.

\subsection{Potential corrosive microorganisms}

The bacterial community information obtained above was further analyzed in terms of their potential function on iron corrosion, which could be useful for understanding the possible roles of microorganisms in iron corrosion (including corrosion scales formation) in DWDS. The relative abundance of bacteria associated with iron corrosion in genus level is listed in Table 3. Corrosive microorganisms were identified in genus level, and the classification was made according to previous published reports, e.g. IOB (Acidovorax, Gallionella, Leptothrix and Sphaerotilus) (Kristina et al., 2004; Emde et al., 1992; Li et al., 2010), SRB (Desulfovibrio, Desulfotomaculum) (Chang et al., 2001), SOB (Acidithiobacillus, Alicyclobacillus) (Jiang et al., 2009). Some functional microorganisms should be classified in species level such as Sulfuricella denitrificans (SOB) (Kojima and Fukui, 2010), Bacillus sp., Clostridium sp., Pseudomonas sp. and Escherichia coli (IRB) (Emde et al., 1992). But the identification to the specie level may not be accurate with the short reads of 454 pyrosequencing.

Some notable characteristics of the corrosive bacteria in the seven samples could be observed. First, the relatively higher abundance of sequences related to Bacillus were detected in samples A, B and C (19.45\%, $15.32 \%$ and $18.66 \%$ respectively). Compared with these three samples, samples F and G contained a much lower proportion of Bacillus $(0.10 \%$, $0.23 \%$ ). The relative content of Bacillus in sample $\mathrm{D}$ and $\mathrm{E}$ were between that of samples with SW and GW, which was 9.03\% and 2.32\% respectively. Previous research reported that a great many species (such as Bacillus sp., Bacillus subterraneus sp. nov., Bacillus circulans, Bacillus polymyxa, Bacillus subtills, Bacillus infernus sp. nov., Bacillus infernus and so on) belonged to Bacillus had the ability to reduce ferric iron to ferrous iron, known as IRB (Kanso et al., 2002; Scala et al., 2006; Khan et al., 2010). In addition to Bacillus, Clostridium, Pseudomonas and Escherichia-Shigella were also identified in the samples, and some species (e.g. Clostridium sp., Pseudomonas sp. E. coli) belonged to these genera were also IRB (Kostka et al., 2002; Emde et al., 1992). Several studies have reported that IRB can generate $\mathrm{Fe}_{3} \mathrm{O}_{4}$ under anaerobic conditions (Roh et al., 2003; Bell et al., 1987). As aforementioned, $\mathrm{Fe}_{3} \mathrm{O}_{4}$ is

Table 3

Relative abundance of potential corrosive microorganisms in genus level in different bacterial communities (\%).

\begin{tabular}{lllllllll}
\hline & Genera & A & B & C & D & E & F & G \\
\hline \multirow{2}{*}{ SRB } & Desulfovibrio & 0.02 & 0.12 & 0.01 & 0.19 & 0.06 & 0.05 & 0.11 \\
& Desulfotomaculum & 0.23 & 0.03 & 0.08 & 0.06 & - & - & 0.02 \\
SOB & Sulfuricella & 0.02 & - & - & 0.03 & 0.30 & 0.02 & - \\
& Acidithiobacillus & 0.07 & - & - & - & - & - & - \\
& Alicyclobacillus & 0.08 & - & - & - & - & - & - \\
IRB & Bacillus & 19.45 & 15.32 & 18.66 & 9.03 & 2.32 & 0.10 & 0.23 \\
& Clostridium & 0.58 & 0.80 & 1.07 & 0.65 & 0.10 & - & - \\
& Pseudomonas & 0.94 & 1.67 & 3.24 & 0.7 & 1.51 & 1.73 & 0.02 \\
& Escherichia-Shigella & 0.24 & 0.06 & - & 0.08 & 0.53 & 0.25 & - \\
IOB & Acidovorax & 0.47 & 0.44 & 3.34 & 2.14 & 0.78 & 0.09 & 0.08 \\
& Gallionella & 0.07 & - & 0.02 & - & 0.03 & - & - \\
& Leptothrix & - & - & - & 0.02 & - & - & 0.01 \\
& Pedomicrobium & 0.08 & - & - & - & - & 0.04 & - \\
\hline
\end{tabular}

(SRB: sulfate reducing bacteria; SOB: sulfur oxidizing bacteria; IRB: iron reducing bacteria; IOB: iron oxidizing bacteria). one of the main constitutes of the hard shell-like layers of corrosion scales in DWDS, but the thin scales had no $\mathrm{Fe}_{3} \mathrm{O}_{4}$ or with much lower content. Therefore, the different abundance of IRB with SW and GW might contribute to the differences of the corrosion scales composition.

Second, the percentages of the genus Acidovorax (known as IOB) in samples A, B, C, D and E $(0.47 \%, 0.44 \%, 3.34 \%, 2.14 \%$ and $0.78 \%$, respectively) were obviously higher than that in sample $\mathrm{F}$ and $\mathrm{G}(0.09 \%$, $0.08 \%$ ). In addition to Acidovorax, other IOB bacteria such as Gallionella, Leptothrix and Sphaerotilus were also detected. IOB could convert ferrous iron to ferric forms, which could be deposited on their cell walls to create voluminous sheaths of iron metabolites (Emde et al., 1992). The extensive tuberculation in the pipes transporting SW and the blends seemed to indicate a significant contribution by IOB. Moreover, previous research reported that the metabolic activity of IOB can also influence the geochemistry of their surroundings, for the IOB can induce ferric hydroxide precipitation as secondary by- product, and the ferric hydroxide may then serve as precursor for more stable iron oxides, such as $\alpha-\mathrm{FeOOH}$ (Konhauser, 1998). Some species belonging to the genus Acidovorax were also shown to produce $\alpha$-FeOOH during the Fe (II) oxidation (Klueglein and Kappler, 2013).

Third, SRB (Desulfovibrio, Desulfotomaculum) and SOB (Acidithiobacillus, Alicyclobacillus and Sulfuricella) were also detected in this study (most of the sequences related to Sulfuricella showed high similarity to Sulfuricella denitrificans), but they were not rich in all biofilm samples, compared with IRB and IOB. In addition, the relative abundance of these potentially corrosive microorganisms in samples with GW was markedly lower than that in other samples.

\subsection{Potential bacterial pathogens}

Several potential opportunistic pathogens were detected in the seven biofilm samples by pyrosequencing analysis (Fig. 2). Notably, Burkholderia and Ralstonia were found in all biofilm samples. Some Burkholderia sequences were closely related to Burkholderia fungorum, and most of the Ralstonia sequences showed high similarity to Ralstonia pickettii. B. fungorum belonging to the Burkholderia cepacia complex had been reported to cause bacteremia and invasive infection (Speert et al., 2002). R. pickettii has gained substantial interests as a nosocomial infections agent in water, water system components, distilled facilities, and potable water dispenser in international space station (Lee et al., 2010).

In comparison with Burkholderia and Ralstonia, Mycobacterium was mainly existed in the samples with SW and blends. Many of the Mycobacterium sequences cannot be classified at the species level, while some Mycobacterium sequences were closely related to Mycobacterium neoaurum and Mycobacterium frederiksbergense. M. neoaurum was found to cause bloodstream infection (Washer et al., 2007), and M. frederiksbergense may cause cutaneous infections (Regnier et al., 2009). Previous research reported that chlorine may facilitate the heavy occurrence of Mycobacteria (Liu et al., 2012b). In this study, the correlation results showed that the relative abundances of Mycobacteria was significantly correlated with temperature $(\mathrm{R}=0.81, \mathrm{p}<0.01)$.

It also should be noticed that Escherichia-Shigella was detected in all the biofilm samples except sample G. All of the Escherichia-Shigella sequences showed high similarity to $E$. coli, which was an indicator of human and animal fecal contamination. The presence of E. coli suggested an undesirable contamination of water systems due to treatment deficiencies or lack of water system integrity, or a possible fecal contamination originated from the source water (Lee et al., 2010). Thus, proper disinfection measures should be considered to insure the microbial safety of drinking water.

\section{Conclusions}

The composition of biofilm communities formed on cast iron corrosion scales under different water supply histories in DWDS were 
investigated by using 454 pyrosequencing of $16 \mathrm{~S}$ rRNA. The following conclusions could be reached:

Compared with the biofilms with SW and blends, biofilms with GW had rather lower bacterial richness and diversity.

Proteobacteria (mainly consisted of Betaproteobacteria) was the dominant phylum in all biofilm samples, but its percentage was relatively higher in biofilms with GW. The relative abundance of Firmicutes in biofilms with SW was significantly higher than that in biofilms with GW ( $<<0.01$ ), and this phyla was primarily comprised of Bacillus.

Statistical analysis revealed that alkalinity and $\operatorname{COD}_{\mathrm{Mn}}$ had positive correlation with Proteobacteria and Firmicutes, respectively.

Sequences related to iron corrosion, such as SRB, SOB, IRB and IOB were detected, and the relative abundances of sequences related to IRB and IOB in biofilms with SW were much higher than those in the biofilms with GW.

The relative abundance of IRB and IOB (classified in genus level) was higher in biofilms with SW, which might contribute to the much thicker and tubercle-formed corrosion scales under surface water source condition.

Some potential opportunistic pathogens such as Mycobacterium, $B$. fungorum and $E$. coli were detected in the biofilm samples, which implicated that efficient biofilm disinfection measures should be considered to insure the microbial safety of drinking water.

\section{Conflict of interest}

All authors declare that there is no actual or potential conflict of interest associated with this manuscript.

\section{Acknowledgments}

This work was financially supported by National Natural Science Foundation of China (No. 51178450 and No. 51025830) and National Water Pollution Control and Treatment Special Key Project of China (2012ZX07404-002 and 2012ZX07408-002).

\section{Appendix A. Supplementary data}

Supplementary data to this article can be found online at http://dx. doi.org/10.1016/j.scitotenv.2013.11.017.

\section{References}

Abecasis AB, Serrano M, Alves R, Quintais L, Pereira-Leal JB, Henriques AO. A genomic signature and the identification of new sporulation genes. J Bacteriol 2013;195: 2101-15.

Bachmann RT, Edyvean RGJ. Biofouling: an historic and contemporary review of its causes, consequences and control in drinking water distribution systems. Biofilms 2005;2:197-227

Bai YH, Shi Q Wen DH, Li ZX, Jefferson WA, Feng CP, et al. Bacterial communities in the sediments of Dianchi lake, a partitioned eutrophic waterbody in China. PLoS One 2012;7:e37796.

Beech IB, Sunner J. Biocorrosion: towards understanding interactions between biofilms and metals. Curr Opin Biotechnol 2004;15:181-6.

Bell PE, Mills AL, Herman JS. Biogeochemical conditions favoring magnetite formation during anaerobic iron reduction. Appl Environ Microbiol 1987;53:2610-6.

Berry D, Xi CW, Raskin L. Microbial ecology of drinking water distribution systems. Curr Opin Biotechnol 2006;17:297-302.

Chang YJ, Peacock AD, Long PE, Stephen JR, Mckinley JP, Macnaughton SJ, et al. Diversity and characterization of sulfate-reducing bacteria in groundwater at a uranium mill tailings site. Appl Environ Microbiol 2001;67:3149-60.

Chao A, Lee SM. Estimating the number of classes via sample coverage. J Am Stat Assoc 1992;87:210-7.

Cottrell MT, Waidner LA, Yu LY, Kirchman DL. Bacterial diversity of metagenomic and PCR libraries from the Delaware River. Environ Microbiol 2005;7:1883-95.

Eichler S, Christen R, Holtje C, Westphal P, Botel J, Brettar I, et al. Composition and dynamics of bacterial communities of a drinking water supply system as assessed by RNAand DNA-based 16S rRNA gene fingerprinting. Appl Environ Microbiol 2006;72: $1858-72$.

Emde KME, Smith DW, Facey R. Initial investigation of microbially influenced corrosion (MIC) in a low-temperature water distribution-system. Water Res 1992;26:169-75.
Feazel LM, Baumgartner LK, Peterson KL, Frank DN, Harris JK, Pace NR. Opportunistic pathogens enriched in showerhead biofilms. Proc Natl Acad Sci U S A 2009;106: 16393-8.

Glockner FO, Fuchs BM, Amann R. Bacterioplankton compositions of lakes and oceans: a first comparison based on fluorescence in situ hybridization. Appl Environ Microbiol 1999;65:3721-6.

Hong P-Y, Hwang C, Ling F, Andersen GL, LeChevallier MW, Liu W-T. Pyrosequencing analysis of bacterial biofilm communities in water meters of a drinking water distribution system. Appl Environ Microbiol 2010;76:5631-5.

Jang HJ, Choi YJ, Ka JO. Effects of diverse of water pipe materials on bacterial communities and water quality in the annular reactor. J Microbiol Biotechnol 2010;21:115-23.

Jiang CY, Liu Y, Liu YY, Guo X, Liu SJ. Isolation and characterization of ferrous-and sulfur-oxidizing bacteria from Tengchong solfataric region, China. J Environ Sci 2009;21:1247-52.

Kanso S, Greene AC, Patel BKC. Bacillus subterraneus sp nov., an iron- and manganesereducing bacterium from a deep subsurface Australian thermal aquifer. Int J Syst Evol Microbiol 2002;52:869-74.

Khan MR, Saha ML, Begum N, Islam MN, Hoque S. Isolation and characterization of bacteria from rusted iron materials. Bangladesh J Bot 2010;39:185-91.

Klueglein N, Kappler A. Abiotic oxidation of Fe(II) by reactive nitrogen species in cultures of the nitrate-reducing Fe(II) oxidizer Acidovorax sp BoFeN1 - questioning the existence of enzymatic Fe(II) oxidation. Geobiology 2013;11:180-90.

Kojima H, Fukui M. Sulfurivella denitrificans gen. nov., sp. nov., a sulfur-oxidizing autotroph isolated from a freshwater lake. Int J Syst Evol Microbiol 2010;60:2862-6.

Konhauser KO. Diversity of bacterial iron mineralization. Earth-Sci Rev 1998;43:91-121.

Korehi H, Blothe M, Sitnikova MA, Dold B, Schippers A. Metal mobilization by iron- and sulfur-oxidizing bacteria in a multiple extreme mine tailings in the Atacama Desert, Chile. Environ Sci Technol 2013:47:2189-96.

Kormas KA, Neofitou C, Pachiadaki M, Koufostathi E. Changes of the bacterial assemblages throughout an urban drinking water distribution system. Environ Monit Assess 2010;165:27-38.

Kostka JE, Dalton DD, Skelton H, Dollhopf S, Stucki JW. Growth of iron(III)-reducing bacteria on clay minerals as the sole electron acceptor and comparison of growth yields on a variety of oxidized iron forms. Appl Environ Microbiol 2002;68:6256-62.

Kristina LS, Wilhelm AS, Berit EEB-C, Bernhard S. Diversity of ferrous iron-oxidizing, nitrate-reducing bacteria and their involvement in oxygen-independent iron cycling. Geochem J 2004;21:371-8.

Lee J, Lee CS, Hugunin KM, Maute CJ, Dysko RC. Bacteria from drinking water supply and their fate in gastrointestinal tracts of germ-free mice: a phylogenetic comparison study. Water Res 2010;44:5050-8.

Li D, Li Z, Yu J, Cao N, Liu R, Yang M. Characterization of bacterial community structure in a drinking water distribution system during an occurrence of red water. Appl Environ Microbiol 2010;76:7171-80.

Liao JS, Fukui H, Urakami T, Morisaki H. Effect of biofilm on ennoblement and localized corrosion of stainless steel in fresh dam-water. Corros Sci 2010;52: 1393-403.

Liu R, Yu Z, Zhang H, Yang M, Shi B, Liu X. Diversity of bacteria and mycobacteria in biofilms of two urban drinking water distribution systems. Can J Microbio 2012a:58:261-70.

Liu R, Yu Z, Guo H, Liu M, Zhang H, Yang M. Pyrosequencing analysis of eukaryotic and bacterial communities in faucet biofilms. Sci Total Environ 2012b;435:124-31.

Lu L, Xing DF, Ren NQ. Pyrosequencing reveals highly diverse microbial communities in microbial electrolysis cells involved in enhanced $\mathrm{H}_{2}$ production from waste activated sludge. Water Res 2012;46:2425-34.

Margulies M, Egholm M, Altman WE, Attiya S, Bader JS, Bemben LA, et al. Genome sequencing in microfabricated high-density picolitre reactors. Nature 2005;437: 376-80.

Martiny AC, Jorgensen TM, Albrechtsen HJ, Arvin E, Molin S. Long-term succession of structure and diversity of a biofilm formed in a model drinking water distribution system. Appl Environ Microbiol 2003;69:6899-907.

Ndiongue S, Huck PM, Slawson RM. Effects of temperature and biodegradable organic matter on control of biofilms by free chlorine in a model drinking water distribution system. Water Res 2005:39:953-64.

Price MN, Dehal PS, Arkin AP. FastTree 2 - approximately maximum-likelihood trees for large alignments. PLoS One 2010;5:e9490.

Regnier S, Cambau E, Meningaud JP, Guihot A, Deforges L, Carbonne A, et al. Clinical management of rapidly growing mycobacterial cutaneous infections in patients after mesotherapy. Clin Infect Dis 2009;49:1358-64.

Reynolds KA, Mena KD, Gerba CP. Reviews of environmental contamination and toxicology. In: Whitacre DW, editor. Risk of waterborne illness via drinking water in the United States. New York: Springer; 2008. p. 117-58.

Roh Y, Zhang C-L, Vali H, Lauf RJ, Zhou J, Phelps TJ. Biogeochemical and environmental factors in Fe biomineralization: magnetite and siderite formation. Clay Clay Miner 2003;51:83-95.

Sarin P, Snoeyink VL, Lytle DA, Kriven WM. Iron corrosion scales: model for scale growth, iron release, and colored water formation. J Environ Eng-Asce 2004;130:364-73.

Scala DJ, Hacherl EL, Cowan R, Young LY, Kosson DS. Characterization of Fe(III)-reducing enrichment cultures and isolation of Fe(III)-reducing bacteria from the Savannah River site, South Carolina. Res Microbiol 2006;157:772-83.

Schwermer CU, Lavik G, Abed RMM, Dunsmore B, Ferdelman TG, Stoodley P, et al. Impact of nitrate on the structure and function of bacterial biofilm communities in pipelines used for injection of seawater into oil fields. Appl Environ Microbiol 2008;74:2841-51.

Simoes LC, Simoes M, Vieira MJ. Influence of the diversity of bacterial isolates from drinking water on resistance of biofilms to disinfection. Appl Environ Microbiol 2010;76:6673-9. 
Speert DP, Henry D, Vandamme P, Corey M, Mahenthiralingam E. Epidemiology of Burkholderia cepacia complex in patients with cystic fibrosis, Canada. Emerg Infect Dis 2002;8:181-7.

Videla HA, Herrera LK. Understanding microbial inhibition of corrosion. A comprehensive overview. Int Biodeter Biodegr 2009;63:896-900.

Wang H, Hu C, Hu X, Yang M, Qu J. Effects of disinfectant and biofilm on the corrosion of cast iron pipes in a reclaimed water distribution system. Water Res 2012;46: 1070-8.

Washer LL, Riddell J, Rider J, Chenoweth CE. Mycobacterium neoaurum bloodstream infection: report of 4 cases and review of the literature. Clin Infect Dis 2007;45:E10-3.

Washizu N, Katada Y, Kodama T. Role of $\mathrm{H}_{2} \mathrm{O}_{2}$ in microbially influenced ennoblement of open circuit potentials for type $316 \mathrm{~L}$ stainless steel in seawater. Corros Sci 2004;46:1291-300
Williams MM, Domingo JWS, Meckes MC, Kelty CA, Rochon HS. Phylogenetic diversity of drinking water bacteria in a distribution system simulator. J Appl Microbiol 2004;96: 954-64.

Wu SG, Wang GT, Angert ER, Wang WW, Li WX, Zou H. Composition, diversity, and origin of the bacterial community in grass carp intestine. PLoS One 2012;7:e30440.

Xu CM, Zhang YH, Cheng GX, Zhu WS. Localized corrosion behavior of 316 L stainless steel in the presence of sulfate-reducing and iron-oxidizing bacteria. Mater Sci Eng A Struct 2007;443:235-41.

Yang F, Shi B, Gu J, Wang D, Yang M. Morphological and physicochemical characteristics of iron corrosion scales formed under different water source histories in a drinking water distribution system. Water Res 2012;46:5423-33.

Zuo RJ, Kus E, Mansfeld F, Wood TK. The importance of live biofilms in corrosion protection. Corros Sci 2005;47:279-87. 